\title{
The third US national climate assessment: innovations in science and engagement
}

\author{
Katharine L. Jacobs ${ }^{1}$ • James L. Buizer ${ }^{2}$ • \\ Susanne C. Moser ${ }^{3,4}$
}

Received: 15 January 2016 / Accepted: 21 January 2016/Published online: 10 February 2016

(C) Springer Science+Business Media Dordrecht 2016

\section{Introduction}

Climate change poses numerous challenges for ecosystems, communities, businesses, and government agencies, and these challenges are becoming more visible across the globe. Over the last decade, conversations focused on documenting, anticipating, and preparing for climate risks have provided significant opportunities for interdisciplinary research and for transdisciplinary community building among scientists and practitioners. While some of these opportunities have become visible to contributors to large-scale, interdisciplinary assessments such as the periodic reports issued by the Intergovernmental Panel on Climate Change (IPCC) they are increasingly evident in national- or smaller-scale assessment efforts as have been conducted in the UK, Australia, Canada, the European Union, and in the United States (US).

The Third US National Climate Assessment (NCA3) report (https://nca2014.globalchange. gov) (Melillo et al. 2014) has garnered international attention due to multiple innovations in both process and products. This Special Issue brings together key lessons learned from the NCA3, not only to inform future US assessment efforts, but also to discuss frankly and share broadly what was done, how it was done, what worked and what did not. Our hope and intention behind pulling these lessons together is that those sponsoring, designing, and assisting in assessments at the regional, national and international levels can benefit from

This article is part of a special issue on "The National Climate Assessment: Innovations in Science and Engagement" edited by Katharine Jacobs, Susanne Moser, and James Buizer.

Katharine L. Jacobs

jacobsk@email.arizona.edu

1 Center for Climate Adaptation Science and Solutions, Soil, Water and Environmental Science, University of Arizona, Tucson, AZ, USA

2 Climate Adaptation and International Development, Institute of the Environment, School of Natural Resources and the Environment, University of Arizona, Tucson, AZ, USA

3 Susanne Moser Research \& Consulting, Stanford University, Santa Cruz, CA, USA

4 Woods Institute for the Environment, Stanford University, Palo Alto, CA, USA 
this experience. Importantly, these articles do not summarize the findings of the NCA3 report itself, but move beyond them to provide insights about the assessment process and outcomes.

\section{Background on US national climate assessments}

Assessments can be useful at multiple scales, from resolving specific scientific issues to broadly integrating a wide range of sources of knowledge. Climate assessments often include consideration of underlying social, economic, and environmental systems as well as projections of trends in climate-related drivers in complex systems. However, in the case of US national assessments, they also serve as the basis for regulation, policy, and decisions about how to manage risks, which means that they must be conducted with extreme care in order to avoid costly errors.

The 1990 Global Change Research Act established the U.S. Global Change Research Program (USGCRP) and included a requirement that a global change assessment be completed at least every four years that integrates, evaluates, and assesses the state of knowledge of current and projected future impacts. ${ }^{1}$ Despite the "at least every 4-years" requirement, only two National Climate Assessments ${ }^{2}$ were conducted between 1990 and 2009. There are a variety of reasons why these reports were not completed in a more timely manner, but an important one is that a great deal of infrastructure and social capital is required to conduct assessments properly, given the need to engage stakeholders and external experts in order to meet legal requirements. The federal government does not have the capacity to assess current and projected climate impacts within all of the required sectors without the assistance of external participants. Nor would an assessment conducted entirely within the federal government be as readily acceptable or useful to stakeholders across the US. Importantly, USGCRP has not historically maintained a staff to support timely completion of assessment reports. Rather, new infrastructure and capacity for conducting assessments have been built up each time to support each of the three NCA efforts (for more detail, see Buizer et al. 2015, this issue).

Multiple other large-scale international assessments of research on the implications of global environmental changes have been conducted over the last decades, including the Arctic Assessment (Arctic Council 2005), the Millennium Ecosystem Assessment (2005), and the Ozone Assessments (World Meteorological Organization 2010). In 2007, the National Research Council issued a report that evaluated the lessons learned across this wide array of assessment activities. The findings of this report were highly influential in the development of

${ }^{1}$ Text of the GCRA (1990), Section 106. SCIENTIFIC ASSESSMENT: On a periodic basis (not less frequently than every 4 years), the Council, through the Committee, shall prepare and submit to the President and the Congress an assessment which-

1. integrates, evaluates, and interprets the findings of the Program and discusses the scientific uncertainties associated with such findings;

2. analyzes the effects of global change on the natural environment, agriculture, energy production and use, land and water resources, transportation, human health and welfare, human social systems, and biological diversity; and

3. analyzes current trends in global change, both human- induced and natural, and projects major trends for the subsequent 25 to 100 years.

2 Though the law refers to these assessments as global change assessments, the USGCRP has chosen to refer to them as National Climate Assessments. However, the context for them is clearly broader than climate. 
the strategy for the NCA3; its recommendations were explicitly considered for its process and products and are reproduced in Textbox 1:

Textbox 1: Essential Elements of Effective Assessments

- A clear strategic framing of the assessment process, including a well-articulated mandate, realistic goals consistent with the needs of decision makers, and a detailed implementation plan.

- Adequate funding that is both commensurate with the mandate and effectively managed to ensure an efficient assessment process.

- A balance between the benefits of a particular assessment and the opportunity costs (e.g., commitments of time and effort) to the scientific community.

- A timeline consistent with assessment objectives, the state of the underlying knowledge base, the resources available, and the needs of decision makers.

- Engagement and commitment of interested and affected parties, with a transparent science-policy interface and effective communication throughout the process.

- Strong leadership and an organizational structure in which responsibilities are well articulated.

- Careful design of interdisciplinary efforts to ensure integration, with specific reference to the assessment's purpose, users' needs, and available resources.

- Realistic and credible treatment of uncertainties.

- An independent review process monitored by a balanced panel of review editors.

- Maximizing the benefits of the assessment by developing tools to support use of assessment results in decision making at differing geographic scales and decision levels.

- Use of a nested assessment approach, when appropriate, using analysis of large-scale trends and identification of priority issues as the context for focused, smaller-scale impacts and response assessments at the regional or local level.

Source: NRC (2007). Analysis of Global Change Assessments: Lessons Learned (http:// books.nap.edu/catalog.php?record_id=11868)

NCA3 was explicitly designed to address some shortcomings of previous assessments as well as to benefit from the lessons learned in National Research Council studies, including the America's Climate Choices series (NRC 2010a, b, c, d, 2011). Some of the more salient criticisms of these previous assessments focused on the limited utility of the material produced for "real-world" contexts and the failure to truly connect with the American public. The NCA3 was also very much influenced by the Obama administration's strong focus on decisionrelevance, transparency, and planning for resilience, and by the 2012 Strategic Plan of the US Global Change Research Program (USGCRP 2012). That plan included "Informing Decisions" "Sustain Assessments" and "Communicate and Educate" as pillars of the research program, in addition to "Advance Science;" the latter had traditionally been the primary focus of USGCRP's 13-agency science effort. This represented a major shift in policy toward "actionable" science in addition to fundamental climate science research conducted under the auspices of the USGCRP and established a firm foundation for the NCA3's engagement strategy (see, Cloyd et al. 2015, this issue).

Another criticism of previous climate assessments was the burden placed on the scientific community from major efforts, such as the every-six-year IPCC assessment reports and previous US national assessments. The thousands of scientists and other experts who contribute to IPCC and the NCA work as volunteers, with a number of important repercussions. This dependence on volunteers affects the potential pool of available participants and the enthusiasm of the people involved, because it means that many of the same people are tapped for these processes time after time (NRC 2007). The lack of funding and other support for 
assessment activities continues to plague the NCA assessment process, and was a serious issue within the NCA3. The use of professional NCA staff to provide a much higher level of support for author teams in NCA3 successfully alleviated some (but certainly not all) concerns about the burden on authors. However, through a more strategic and sustained effort, the burden on the scientific community could be further reduced (Buizer et al. 2015, this issue).

\section{Overview of contributions to this special issue}

This special issue explores the NCA3 as compared with previous assessments from both process and content perspectives. Among the NCA3's important contributions are its emphasis on interdisciplinary learning and the introduction of an engagement strategy that brought hundreds of public and private sector contributors and stakeholders into the assessment community. The NCA3 also included an explicit focus on building sustained assessment capacity, an adaptive approach to managing assessments, and analyzing both the impacts of climate on cross-sectoral systems and the intertwined and cascading effects across sectors. Many new lessons were learned within these efforts and they are discussed in detail in this issue. The first set of articles in this issue describe these NCA3 innovations in some detail. Building Community, Credibility and Knowledge: the Third US National Climate Assessment (Jacobs and Buizer 2015, this issue), includes a broad discussion of the role of assessments in general and the NCA3 in particular in framing our understanding of change. The next two papers delve further into process innovations.

Building a Sustained Assessment Process (Buizer et al. 2015, this issue) discusses the rationale for building the infrastructure and capacity for ongoing assessment activities that support a wide range of research and application goals. It provides insights beyond those included in a special report on this topic that was delivered to the USGCRP by the federal advisory committee for the NCA3: Preparing the Nation for Change: Building a Sustained National Climate Assessment Process (Buizer et al. 2013).

Engagement in the Third U.S. National Climate Assessment, by Cloyd et al. (2015, this issue) describes both the motivation and the approach used in the NCA3 to build a broad assessment community of scientists, contributors, and stakeholders in regions and sectors across the U.S. Partly because of the broad interest by the public, private, and nongovernmental sectors in the activities and conclusions of the assessment, and partly because of the high degree of scrutiny of the process, the entire NCA3 effort was built in the context of balancing the interests of multiple kinds of decision-makers, scientists, and government agencies. A key goal of these engagement efforts was to develop active partnerships that could bring relevant information to the assessment and communicate its findings to audiences and decision-makers across sectors and regions. The authors argue that these partnerships are an essential part of building a sustained assessment process. As many assessment leaders and observers have learned over the past two decades or more, in order for assessment findings to be truly useful from a decision-maker's perspective, the decision-makers themselves need to be part of the process.

The second set of papers focuses on innovations in the assessment process itself that were intended to build assessment capacity over time. To do so, considerable investments were made in producing consistent climate histories and future projections for each of eight US regions and a national set of sea-level-rise projections to allow for comparisons across the 
nation and to integrate regions and sectors within a common "risk management" framework. Kunkel and colleagues, in their paper, Innovations in Science and Scenarios for Assessment (2015, this issue), describe the intent, process, and challenges in doing so. To make such climate histories and projections accessible for impact assessors as well as for downstream users of such information, a significant effort was undertaken during the NCA3 to invest in data management and accessibility, as described by Waple et al. (2016, this issue) in Innovations in Information Management and Access for Assessments. This article describes the ongoing efforts of the federal agencies to build a global change information system and to provide transparent access to the data behind each of the major conclusions of the NCA3. The third comprehensive investment in sustained assessment capacity by federal agencies was the development (still ongoing) of an integrated set of national indicators of change across social, physical, and ecological systems and of adaptive responses as described by Kenney and colleagues in Building an Integrated National Climate Indicators System (2016, this issue).

The NCA3 also stands out for its considerable effort to integrate across sectors, disciplines, practitioner perspectives and different forms of knowledge systems. Various illustrations of this approach to assessing risk and the status of adaptive responses are provided in the next three articles: first, assessing ecosystem impacts and services in Climate Change Impacts on Ecosystems and Ecosystem Services in the United States (Grimm et al. 2015, this issue); the implications of climate change on indigenous peoples and their lands and traditional cultural resources in Engagement with Indigenous Peoples and Honoring Traditional Knowledge Systems (Maldonado et al. 2015, this issue); and the integrated social, physical and ecological implications of climate change in coastal areas in The Third National Climate Assessment's Coastal Chapter (Moser and Davidson 2015, this issue). Each author team in this set pursued a different path to the goal of providing new insights on the complexities of climate change impacts in the "real world." The collective lessons learned are useful in putting together future assessment teams, designing and supporting assessments, and for connecting these assessments to adaptation processes both within the US and internationally.

Specifically on the question of how assessments should be framed to elevate their decisionrelevance and increase their ability to support decisions, Moss (2015, this issue) describes in Assessing Decision Support Systems and Levels of Confidence to Narrow the Climate Information "Usability Gap" how important, and yet how difficult it was for NCA3 to improve on past approaches and conventions for assessing scientific confidence and uncertainty. The article makes a strong case for why sustained assessment capacity needs to be built, and why learning from ongoing decision-support efforts, successes, and failures, must be an integral part in improving assessments over time. The article also reviews challenges and approaches for characterizing uncertainties and communicating confidence of lead authors in findings based on the best available - but still incomplete - scientific evidence.

A critical reason for ongoing assessment of the state of knowledge is that both the climate and our understanding of the mechanisms of change are evolving. It is important to evaluate how assessments can support adaptation and adaptive management by taking the perspective of decision-makers who are working toward more resilient systems. In "Innovations in Assessment and Adaptation," Howden and Jacobs (2015, this issue) explore different aspects of the adaptation process and their respective information needs, and suggest some paths forward in building future assessments that address particularly challenging aspects of adaptation.

Finally, the Liverman article (2015, this issue), U.S. National Climate Assessment Gaps and Research Needs, discusses critical areas for improving the underlying science foundation for 
future assessments. The paper does not delineate the typical wish list of research needs from across all common climate science subfields. Rather, it brings into focus two particularly important gaps in knowledge that both limit the understanding of key future vulnerabilities of the US and could undermine adequate preparedness efforts. They are: (a) the need to identify and characterize international linkages that can either amplify or attenuate locally experienced climate risks, and (b) the significant lack of understanding of climate change impacts on the biggest sectors of the economy (such as manufacturing or service industries), as opposed to focusing only on some of the most climate-sensitive sectors (such as agriculture).

In the concluding paper for this special issue, Aspirations and Common Tensions: Larger Lessons from the US National Climate Assessment, Moser et al. (2015, this issue) synthesize high-level, integrative lessons from the NCA3, based on the more specific messages and recommendations outlined in each of the preceding papers. We hope these are of wider interest to future US assessment designers and participants and to the international assessment community. They focus on the key ingredients of assessments, including the process, the supporting institutional infrastructure and resource base, the scientific information and foundational data, as well as the people who carry out assessments. These reflections provide frank and detailed insights into the making of the NCA3. Clearly, many of its innovations were improvements over past approaches, building on the extensive national and international experience of its participants. But the NCA3 effort should be viewed as a benchmark and a learning experience to be further improved on in future assessments. The concluding paper points the way to further improvements and invites other assessment designers and leaders to share their experiences for collective learning.

Perhaps the most important message emanating from all the papers in this Special Issue, however, is the importance of not losing momentum in a national climate assessment process that is intended to be sustained, partly because climate risks are evolving so rapidly and partly because the concurrent information needs of users at all levels of government and beyond are also expanding over time. Our perspective is that ongoing assessment processes would be advisable elsewhere in the world as well, and thus it is important that this first "experiment" in building assessment capacity continues to make contributions to climate resilience both nationally and globally over time.

Acknowledgments The Guest Editors for this Special Issue are very grateful to the Editors of Climatic Change, Gary Yohe and Michael Oppenheimer, for their support during this process and for their particular interest in our subjects. We thank Kristin Kuntz-Duriseti and Simon Donner for working through each one of these articles with us and answering our endless questions. We are especially grateful for the help of Mary Black of the University of Arizona/Center for Climate Adaptation Science and Solutions for her expert editing support and to the reviewers for the hours spent providing thoughtful comments. Finally, but most importantly, we are so grateful to all of the authors of these papers, who generously shared their time and insights in developing this collection. Most of them were also intimately involved in the rigors of developing the Third National Climate Assessment, and we are glad that despite those adventures they were still willing to work with us on this Special Issue to harvest our collective lessons learned.

\section{References}

Arctic Council (2005) Arctic climate impact assessment-scientific report. Cambridge University Press, Cambridge, 1046 pp

Buizer J, Fleming P, Hays SL, Dow K, Field CB, Gustafson D, Luers A, Moss RH (2013) Preparing the nation for change: building a sustained National Climate Assessment process. National Climate Assessment and Development Committee, US Global Change Research Program. 
Buizer JL, Dow K, Black ME, Jacobs KL, Waple A, Moss RH, Moser S, Luers A, Gustafson DI, Richmond TC, Hays SL, Field CB (2015) Building a sustained climate assessment process. Clim Chang. doi:10.1007/ s10584-015-1501-4

Cloyd E, Moser SC, Maibach E, Maldonado J, Chen T (2015) Engagement in the third U.S. national climate assessment: commitment, capacity, and communication for impact. Clim Chang. doi:10.1007/s10584-015$1568-y$

Grimm NB, Groffman P, Staudinger M, Tallis H (2015) Climate change impacts on ecosystems and ecosystem services in the United States: process and prospects for sustained assessment. Climatic Change. doi:10.1007/ s10584-015-1547-3

Howden M, Jacobs K (2015) Innovations in assessment and adaptation: building on the US national climate assessment. Climatic Change. doi:10.1007/s10584-015-1519-7

Jacobs KL, Buizer JL (2015) Building community, credibility and knowledge: the third US national climate assessment. Clim Chang. doi:10.1007/s10584-015-1445-8

Kenney MA, Janetos AC, Lough G (2016) Building an integrated U.S. national climate indicators system. Clim Chang. doi:10.1007/s10584-016-1609-1

Kunkel KE, Moss R, Parris A (2015) Innovations in science and scenarios for assessment. Clim Chang. doi:10. 1007/s10584-015-1494-Z

Liverman D (2015) U.S. national climate assessment gaps and research needs: overview, the economy and the international context. Clim Chang. doi:10.1007/s10584-015-1464-5

Maldonado J, Bull Bennett TM, Chief K, Cochran P, Cozzetto K, Gough B, Hiza Redsteer M, Lynn K, Maynard N, Voggesser G (2015) Engagement with indigenous peoples and honoring traditional knowledge systems. Clim Chang. doi:10.1007/s10584-015-1535-7

Melillo JM, Richmond TC, Yohe GW (eds) (2014) Climate change impacts in the United States: the third national climate assessment. U.S. Global Change Research Program, 841 pp. (NCA 3 report) https:// nca2014.globalchange.gov

Millennium Ecosystem Assessment (2005) Ecosystems and human well-being. Island Press, Washington, DC

Moser SC, Davidson MA (2015) The third national climate assessment's coastal chapter: the making of an integrated assessment. Clim Chang. doi:10.1007/s10584-015-1512-1

Moser SC, Melillo JM, Jacobs KL, Moss RH, Buizer JL (2015) Aspirations and common tensions: larger lessons from the third US national climate assessment. Climatic Change. doi:10.1007/s10584-015-1530-z

Moss RH (2015) Assessing decision support systems and levels of confidence to narrow the climate information "usability gap". Clim Chang. doi:10.1007/s10584-015-1549-1

National Research Council (2007) Analysis of global change assessments: lessons learned. National Academies Press, Washington, D.C., 198 pp

National Research Council (2010a) America's climate choices: adapting the impacts of future climate change. National Academies Press, Washington, D.C., 292 pp

National Research Council (2010b) America's climate choices: advancing the science of climate change. National Academies Press, Washington, D.C., 528 pp

National Research Council (2010c) America's climate choices: informing an effective response to climate change. National Academies Press, Washington, D.C., 276 pp

National Research Council (2010d) America's climate choices: limiting the magnitude of future climate change. National Academies Press, Washington, D.C., 276 pp

National Research Council (2011) America's climate choices. National Academies Press, Washington, D.C

U.S. Global Change Research Program (2012) The National Global Change Research Plan 2012-2021: a strategic plan for the U.S. Global Change Research Program. USGCRP Report. http://data.globalchange. gov/assets/d0/67/6042585bce196769357e6501a78c/usgcrp-strategic-plan-2012.pdf

Waple AM, Champion SM, Kunkel KE, Tilmes C (2016) Innovations in information management and access for assessments. Clim Chang. doi:10.1007/s10584-015-1588-7

World Meteorological Organization (2010) Scientific assessment of ozone depletion. World Meteorological Organization, Global Ozone Research and Monitoring Project, Report no. 52. http://www.esrl.noaa.gov/ csd/assessments/ozone/2010/report.htm 